\title{
Evaluation of Diagnostic Significance of Certain Symptoms and Physical Signs in Anaemic Patients
}

\author{
AUDREY A. DAWSON,* M.D., M.R.C.P.ED.; D. OGSTON, $\dagger$ M.B., PH.D., M.R.C.P.(LOND., ED.) \\ H. W. FULLERTON, $\ddagger$ M.D., F.R.C.P.(LOND., ED.), F.C.PATH.
}

British Medical fournal, 1969, 3, 436-439

\begin{abstract}
Summary : In a study of 133 anaemic and 111 nonanaemic hospital patients pallor of recent onset was the only symptom which was significantly associated with the severity of the anaemia. Dizziness in acute blood loss anaemia, and anorexia and painful tongue in vitamin- $B_{12}$ deficiency, were the only symptoms which might be helpful in diagnosing the type of anaemia. The frequency of glossitis in patients with megaloblastosis was confirmed, but neither glossitis nor nail changes were significantly more common in patients with iron-deficiency anaemia than in the control patients.
\end{abstract}

\section{Introduction}

Several symptoms and signs are believed to be common in anaemic patients (Britton, 1963; Wintrobe, 1967). Though the stress laid on clinical features in the diagnosis of the presence and type of anaemia is diminishing, they are still used widely in clinical practice. It is important, therefore, that their limitations and value should be appreciated. In this study we have attempted to determine in a population of hospital patients which symptoms and signs might be helpful in detecting the presence of anaemia and in diagnosis of its type.

\section{Patients and Methods}

One hundred and thirty-six anaemic patients admitted consecutively to the medical wards of Aberdeen Royal Infirmary were included in the survey. So far as was possible, they were studied shortly after admission and before the haemoglobin level was known to the observer. Details from 133 patients ( 65 men and 68 women) were analysed. One hundred and eleven non-anaemic hospital patients admitted to a general medical ward over the same period as the anaemic patients were used as controls. The two groups were matched approximately for age and sex (Table I).

TABLE I.-Age and Sex Distribution of Anaemic and Control Patients

\begin{tabular}{c|c|c|c|c|c|c}
\hline $\begin{array}{c}\text { Age } \\
\text { Group }\end{array}$ & \multicolumn{3}{|c|}{ Anaemic Patients } & \multicolumn{3}{|c}{ Control Patients } \\
\cline { 2 - 6 } (Years) & Male & Female & Total & Male & Female & Total \\
\hline 50 & 16 & 15 & 31 & 17 & 12 & 29 \\
$50-69$ & 31 & 32 & 63 & 24 & 28 & 52 \\
$70+$ & 18 & 21 & 39 & 10 & 20 & 30 \\
\hline All.. & 65 & 68 & 133 & 51 & 60 & 111 \\
\hline
\end{tabular}

\section{Haematological Methods}

The haemoglobin level was measured as cyanmethaemoglobin on capillary blood. A stained blood film was examined in every case, and the mean corpuscular haemoglobin concentration (M.C.H.C.) calculated in most of them. Sternal marrow

* Senior Lecturer in Medicine, University of Aberdeen.

$t$ Lecturer in Medicine, University of Aberdeen.

$¥$ Regius Professor of Medicine, University of Aberdeen. aspirates were obtained when required for diagnosis. Serum vitamin $B_{12}$ and serum folate levels were assayed microbiologically by the methods of Spray (1955) and of Waters and Mollin (1961) with Lactobacillus leichmannii and $L$. casei, respectively. The lower limits of normal for the laboratory were $160 \mu \mu \mathrm{g} . / \mathrm{ml}$. for serum vitamin $\mathrm{B}_{12}$ and $4 \mathrm{~m} \mu \mathrm{g} . / \mathrm{ml}$. for serum folate.

\section{Classification of Anaemia}

The anaemic patients had haemoglobin levels of less than $10.9 \mathrm{~g} . / 100 \mathrm{ml}$. (75\% of normal), the control patients of more than $11.7 \mathrm{~g} . / 100 \mathrm{ml}$. (80\%). Six types of anaemia were identified.

(1) Chronic Iron-deficiency Anaemia (46 patients). - In three of the patients this resulted from intestinal malabsorption, while in the remaining 43 it was caused primarily by chronic blood loss, usually from the gastrointestinal tract. A low dietary intake of iron was a contributory factor in some patients. Serum iron, iron-binding capacity, and percentage saturation (Ramsay, 1957a, 1957b) were measured in about half the patients; in these sideropenia was confirmed.

(2) Acute Blood Loss (20 patients).-This resulted from gastrointestinal haemorrhage in 18 patients, from genitourinary bleeding in one, and from profuse haemorrhage after dental extraction in one.

(3) Chronic Renal Failure (14 patients).-All had evidence of long-standing azotaemia ; the blood urea level ranged from 60 to $300 \mathrm{mg} . / 100 \mathrm{ml}$.

(4) Marrow Infiltration (21 patients).-This group consisted of patients with anaemia due to marrow involvement in leukaemia, reticulosis, metastatic carcinoma, myelomatosis, and myelofibrosis.

(5) Vitamin- $B_{12}$ Deficiency (20 patients).-All had megaloblastic marrow smears. Addisonian pernicious anaemia was proved in 16 patients by finding a histamine-fast achlorhydria and serum parietal cell antibodies and by the Schilling test, with and without oral intrinsic factor; post-gastrectomy vitamin- $\mathrm{B}_{12}$ malabsorption was diagnosed in three, and jejunal diverticulosis in one. The serum vitamin- $\mathrm{B}_{12}$ level was less than $160 \mu \mu \mathrm{g} . / \mathrm{ml}$. in every patient in this group.

(6) Folic Acid Deficiency (12 patients).-In this group folate deficiency was thought to be the main cause of anaemia. The group included patients with dietary folate deficiency, idiopathic steatorrhoea, and megaloblastosis associated with anticonvulsant and methotrexate therapy. All had a serum folate level of less than $2.5 \mathrm{~m} \mu \mathrm{g} . / \mathrm{ml}$.

\section{Interview and Examination Technique}

All interviews and examinations were carried out by two observers (A. A.D. and D. O.), using a standardized method of questioning and examination. Each patient was asked about the presence and duration of pallor, fatigue, headache, insomnia, paraesthesiae, dizziness, dyspepsia, constipation, diarrhoea, 
weight loss, and the occurrence of a painful tongue. Weight loss was regarded as significant when more than $7 \mathrm{lb}$. $(3 \cdot 2 \mathrm{~kg}$.) had been lost-without intentional dieting-in the previous six months or less.

The physical signs looked for were changes in the fingernails, vitiligo, glossitis, diminution or loss of vibration sense, fever, and the height and weight.

The finger-nail appearance was classified into grade 0 , normal ; grade 1, loss of lustre, with nail softening; grade 2, exaggeration of grade 1 changes, and flattening of nails; and grade 3, koilonychia. Longitudinal ridging of the nails was disregarded.

Vitiligo was accepted if there was no evidence of previous trauma to account for depigmentation.

Glossitis was regarded as present if the tongue was red and inflamed, or smooth, with atrophy of the filiform papillae, and as equivocal $( \pm)$ if the changes were minor or confined to the tip of the tongue.

Vibration sense was tested with a standard tuning-fork (C128), on the medial malleolus of the ankle. When the vibration sense was equivalent to that of the observer it was recorded as normal ; impaired vibration sense was classified as diminished or absent. Testing of vibration sense in two of the anaemic patients was omitted.

Fever was graded according to the maximum recorded temperature occurring between admission and examination; grade 0 , below $98.4^{\circ} \mathrm{F}$. $\left(36.9^{\circ}\right.$ C.) ; grade 1 , up to $100^{\circ} \mathrm{F}$. $\left(37.8^{\circ}\right.$ C. $)$; and grade 2 , over $100^{\circ}$ F. $\left(37 \cdot 8^{\circ}\right.$ C. $)$.

The height and weight were measured to the nearest $\frac{1}{2}$ in. $\left(1.25 \mathrm{~cm}\right.$.) and $\frac{1}{4} \mathrm{lb} .(0 \cdot 11 \mathrm{~kg}$.), respectively, in 126 anaemic and in 109 control patients. The height: weight ratio was calculated as a percentage of normal for age and sex, based on data by Kemsley et al. (1962). Height-for-weight standards were available for patients up to the age of 65 . We have used the adjustments given for the age group 60-64 years to calculate the observed standard ratio for older patients.

\section{Results}

Table II relates the incidence of recent symptoms to the haemoglobin level in anaemic patients, a haemoglobin level of $8 \mathrm{~g} . / 100 \mathrm{ml}$. (55\%) being an arbitrary dividing line. Pallor of recent onset was found to be the only symptom which showed a significantly higher incidence in the more severely anaemic group. Seven patients said they had always been pale.

The incidence of symptoms relating to the type of anaemia is shown in Table III. Data are also given on the mean haemoglobin level, mean age, and sex distribution of the patients with each type of anaemia. A number of symptoms were related to the type of anaemia. A high proportion of patients with acute blood loss complained of dizziness and dyspepsia, and of those with vitamin- $\mathrm{B}_{12}$ deficiency of anorexia and painful tongue. The relatively low incidence of recent weight loss in patients suffering from acute blood loss anaemia contrasted with its high incidence in all other types of anaemia. The absence of an increased incidence of painful tongue in patients with iron deficiency was also noted. Six patients, of whom four had folate deficiency, commented spontaneously on the episodic nature of the painfulness of the tongue.

TABLE II.-Symptoms Related to Haemoglobin Level in Anaemic

\begin{tabular}{|c|c|c|c|c|c|c|}
\hline \multirow{2}{*}{\multicolumn{2}{|c|}{ Symptom }} & \multicolumn{2}{|c|}{$\begin{array}{c}\text { Haemoglobin under } \\
8 \mathrm{~g} . / 100 \mathrm{ml} . \\
(\mathrm{n}=63)\end{array}$} & \multicolumn{2}{|c|}{$\begin{array}{c}\text { Haemoglobin } \\
8 \mathrm{~g} . / 100 \mathrm{ml} . \\
(\mathrm{n}=70)\end{array}$} & \multirow[t]{2}{*}{$x^{2}$} \\
\hline & & No. & $\%$ & No. & $\%$ & \\
\hline $\begin{array}{l}\text { Recent pallor } \\
\text { Fatigue } \\
\text { Recent headache } \\
\text { Recent insomnia } \\
\text { Paraesthesiae } \\
\text { Dizziness . . } \\
\text { Dyspnoea . } \\
\text { Ankle swelling } \\
\text { Angina } \quad . \\
\text { Palpitations . } \\
\text { Anorexia } . \\
\text { Dyspepsia . } \\
\text { Recent constipation } \\
\text { Diarrhoea . } \\
\text { Weight loss . } \\
\text { Painful tongue }\end{array}$ & $\begin{array}{l}\ldots \\
\cdots \\
\cdots \\
\cdots \\
\cdots \\
\cdots \\
\because \\
\cdots \\
\cdots \\
\cdots\end{array}$ & $\begin{array}{l}53 \\
57 \\
12 \\
14 \\
14 \\
34 \\
40 \\
21 \\
10 \\
18 \\
33 \\
16 \\
11 \\
14 \\
33 \\
10\end{array}$ & $\begin{array}{l}84 \cdot 1 \\
90 \cdot 5 \\
19 \cdot 0 \\
22 \cdot 2 \\
22 \cdot 2 \\
54 \cdot 0 \\
63 \cdot 5 \\
33 \cdot 3 \\
15 \cdot 9 \\
28 \cdot 6 \\
52 \cdot 4 \\
25 \cdot 4 \\
17 \cdot 5 \\
22 \cdot 2 \\
52 \cdot 4 \\
15 \cdot 9\end{array}$ & $\begin{array}{r}27 \\
59 \\
10 \\
12 \\
9 \\
28 \\
34 \\
20 \\
13 \\
15 \\
27 \\
24 \\
9 \\
9 \\
25 \\
8\end{array}$ & $\begin{array}{l}38 \cdot 6 \\
84 \cdot 6 \\
14 \cdot 3 \\
17 \cdot 1 \\
12 \cdot 9 \\
40 \cdot 0 \\
48 \cdot 6 \\
28 \cdot 6 \\
18 \cdot 6 \\
21 \cdot 4 \\
38 \cdot 6 \\
31 \cdot 3 \\
12 \cdot 9 \\
12 \cdot 9 \\
35 \cdot 7 \\
11 \cdot 4\end{array}$ & $\begin{array}{l}26.84 * \\
0.65 \\
0.25 \\
0.27 \\
1.43 \\
2.07 \\
2.42 \\
0.16 \\
0.03 \\
0.56 \\
2.03 \\
0.86 \\
0.25 \\
1.43 \\
3.10 \\
0.24\end{array}$ \\
\hline
\end{tabular}

$\chi^{2}$ was calculated for the difference in incidence of each symptom by haemoglobin evel. Each has one degree of freedom, and Yates's correction for continuity has * $\mathrm{P}<0.01$.

Nail Changes.-Grade 3 nail changes (koilonychia) were found in five anaemic patients and in one control. The latter, though not anaemic, had had a previous gastrectomy. Only two of the patients with chronic iron deficiency had koilonychia. A single example of koilonychia was noted in each of the groups of patients with acute blood loss, chronic renal failure, and vitamin- $\mathrm{B}_{12}$ deficiency. For the purpose of analysis the group of patients with koilonychia were combined with the group showing grade 2 changes. No significant difference in the incidence of nail changes was noted between control and anaemic patients $\left(\chi^{2}=0.47\right.$, d.f. $\left.=2, P>0.5\right)$ nor in the presence or absence of nail changes in the patients with the six types of anaemia $\left(\chi^{2}=6.47\right.$, d.f. $\left.=5, P>0.2\right)$.

Vitiligo.-It was notable that vitiligo was not present in any of the controls, whereas it was present in six anaemic patients, three of whom had folate deficiency, two vitamin- $B_{12}$ deficiency, and one acute blood loss resulting from peptic ulceration.

TABLE III.-Symptoms Related to Type of Anaemia

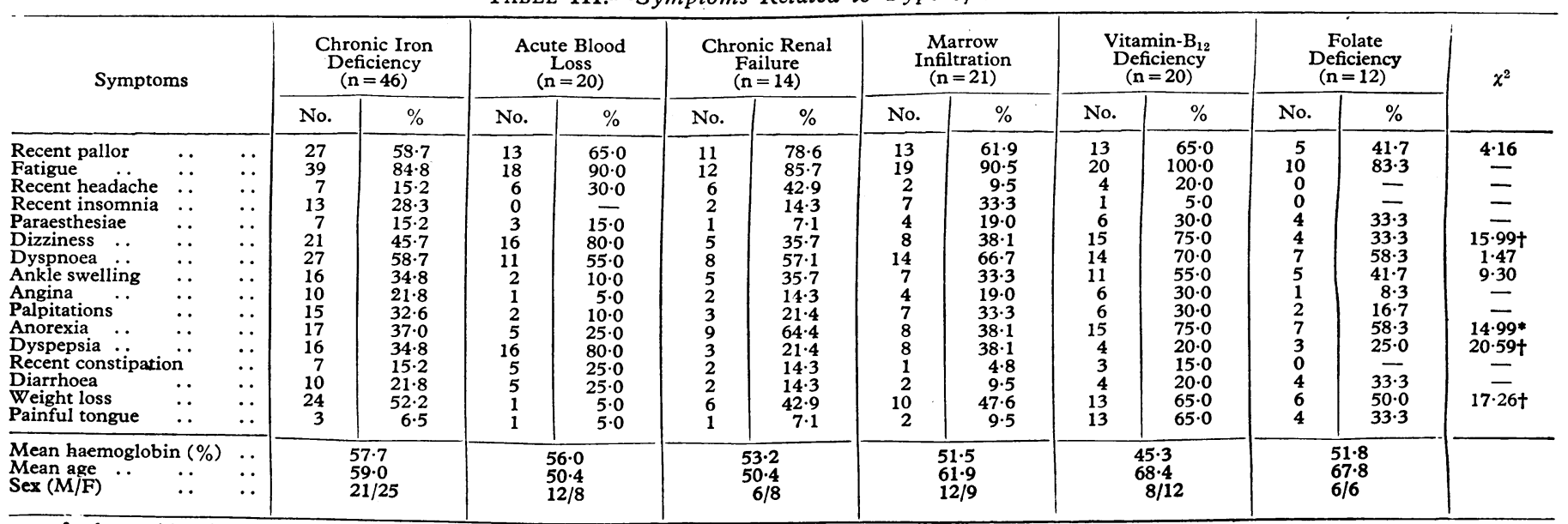

$x^{2}$ values, with 5 degrees of freedom, have been calculated for the differences in incidence of those symptoms in which the numbers are large enough for this calculation.
$* 0.05>\mathrm{P}>0.01$. 
Glossitis.-Glossitis was significantly more common in anaemic than in control patients $\left(\chi^{2}=7 \cdot 18\right.$, d.f. $=2,0.05>\mathrm{P}>$ $0.01)$. Unequivocal glossitis was most common in patients who were deficient in vitamin $\mathrm{B}_{12}$ and folate, and of whom only a minority had normal tongues (Fig. 1). In contrast, only $6.5 \%$ of patients with iron-deficiency anaemia had major glossitis. Increasing anaemia did not alter the incidence of glossitis. Complaint of a painful, dry tongue was as common in control as in anaemic patients.

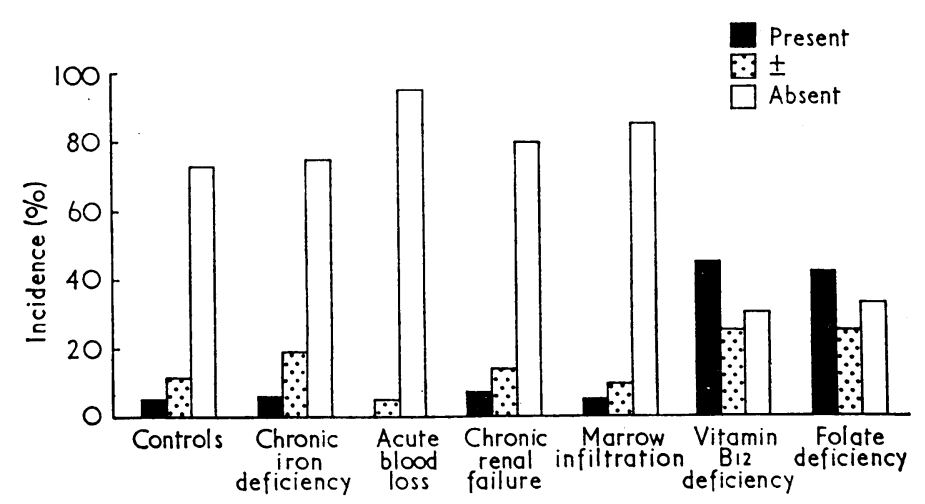

FIG. 1.-Incidence of glossitis in anaemic and control patients.

Vibration Sense.-No difference was found in the absence or impairment of this modality between anaemic and control patients $\left(\chi^{2}=0.21\right.$, d.f. $=2, P>0.5$; the incidence of loss of vibration sense in the patients with the different types of

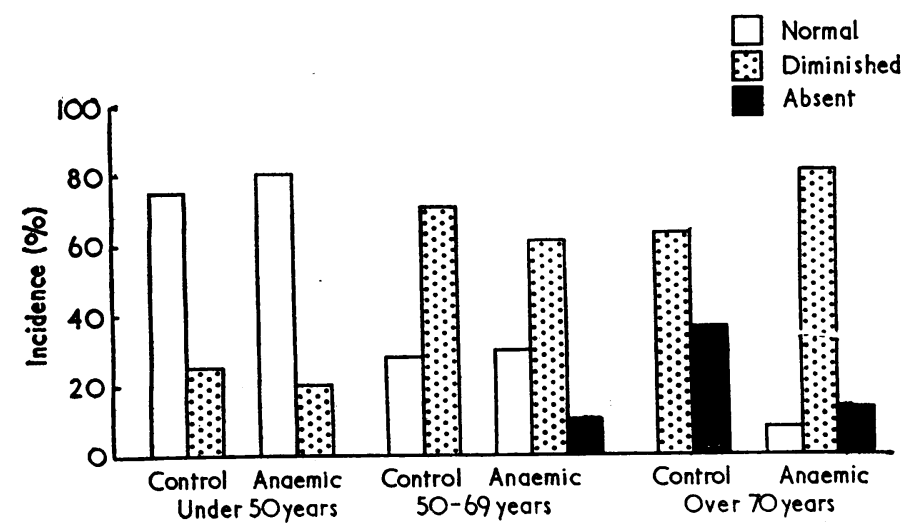

FIG. 2.-Influence of age on vibration sense in anaemic and control patients.

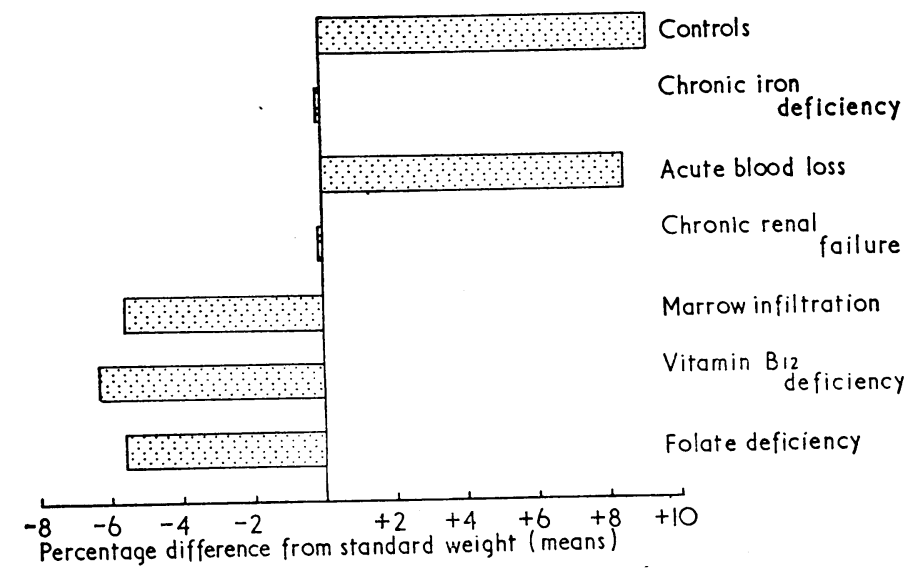

FIG. 3.-Standard weight changes in anaemic and control patients.

anaemia did not reach statistical significance $\left(\chi^{2}=10 \cdot 58\right.$, d.f. $=5$, $0.1>P>0.05)$. The severity of anaemia was also not associated with an increased incidence of changes in the vibration sense.
In both anaemic and control patients, however, there was strong evidence of age-dependence, complete loss of vibration sense rising steeply in incidence with increasing age (Fig. 2). The incidence of intact vibration sense in all patients over the age of 70 was $4 \%$, and in patients with avitaminosis- $B_{12}$ of the same age it was $11 \%$.

Fever.-Fever was more common in anaemic than in control patients ; this difference is highly significant $\left(\chi^{2}=1455\right.$, d.f. $=$ $2, P<0.001)$, though the type of anaemia associated with the presence of fever was not significant $\left(\chi^{2}=10 \cdot 20\right.$, d.f. $=5,0 \cdot 1>$ 0.05 ). Fever was no more common in severely anaemic patients (haemoglobin less than $8 \mathrm{~g} . / 100 \mathrm{ml}$.) than in the moderately anaemic.

Height : Weight Ratios.-The control patients were, on average, $9 \cdot 2 \%$ overweight for their height, while the anaemic patients were within $1 \%$ of their standard weight. This was true of each of the age groups tested (those under 50, between 50 and 69, and of 70 years and over). Of the anaemic group, only patients with acute blood loss were overweight (Fig. 3). The severity of the anaemia was not associated with a change in the height: weight ratio.

\section{Discussion}

Several of the symptoms studied are common to many diseases. This prevented a valid comparison of the incidence of symptoms between unselected anaemic and non-anaemic hospital patients being made. We have assumed, therefore, that the incidence of a symptom related to anaemia per se should be greater when anaemia is severe than when it is moderate. Pallor occurring recently was found to be the only symptom related to the severity of the anaemia. This positive correlation between the recent onset of pallor and a falling haemoglobin confirms the finding of Wood and Elwood (1966) in the women of their community survey. Some symptoms were particularly prominent in one type of anaemia. Most of these can be explained by the nature of the causative disease-for example, dyspepsia and acute blood loss have peptic ulceration as a common factor. The nonspecific nature of some of the symptoms related to a particular type of anaemia-for example, insomnia and headache-minimizes their diagnostic value.

The incidence of painful tongue in iron-deficiency anaemia has been variously reported as $20 \%$ of 50 cases (Witts, 1930), $32 \%$ of 25 cases (Wintrobe and Beebe, 1933), 36\% of 125 cases (Davidson and Fullerton, 1938), and only $11 \%$ of 371 cases (Beveridge et al., 1965). The incidence in our series was $6.5 \%$ of 46 cases. In contrast, in vitamin- $\mathrm{B}_{12}$-deficient patients sore tongue occurred in $65 \%$ of 20 cases. This is in keeping with the figure of $50 \%$ suggested by Britton (1963), though Hall (1965) found the symptom in only $10 \%$ of his patients with pernicious anaemia. Though glossitis was much more common in anaemic patients, it was found in a substantial number of the controls. This fact must be considered when assessing the importance of this sign in the individual patient. The incidence of glossitis in chronic iron-deficiency anaemia (26\%) was less frequent than the $39 \%$ in the series reported by Beveridge et al. (1965). The high incidence in the other dyshaemopoietic anaemias was confirmed, suggesting that glossitis remains a valuable sign of vitamin- $\mathrm{B}_{12}$ and folate deficiency.

A history of weight loss was a common symptom in all the groups of anaemic patients, with the exception of those with acute blood loss. This was reflected in the finding that, apart from those with acute blood loss, all the groups of anaemic patients were below the standard weight; patients with chronic iron deficiency and chronic renal failure, however, were only marginally below this level. In many cases weight loss was clearly the result of the underlying disease causinis the anaemia, rather than a feature of anaemia per se. Our finding of weight loss in 10 of the 16 patients with Addisonian pernicious anaemia is in keeping with other reports which have stressed its fre- 
quency (Jones, 1938 ; Read and Asher, 1956 ; Seaton and Goldberg, 1960 ; Hall, 1965).

Koilonychia and dystrophic nail changes of lesser severity have long been regarded as characteristic of chronic iron deficiency (Witts, 1930 ; Davies, 1931), and this has been restated recently by Jacobs (1969). In this study the incidence of koilonychia in patients with iron-deficiency anaemia was much lower than in previously reported series, but it was not possible to compare the incidence of lesser nail changes because of the differing criteria used. In the present series the incidence of nail changes was not significantly different from that in control subjects, some of whom may have been sideropenic. We conclude, therefore, that nail changes, though they may be a feature of sideropenia, are not helpful evidence of iron-deficiency anaemia in a clinical situation.

Vitiligo was found only in anaemic patients, particularly those with deficiency of vitamin- $\mathrm{B}_{12}$ and folate. Its rarity, however, diminishes its importance as a helpful diagnostic sign in anaemia.

In view of the age-dependence of impairment of vibration sense, both in anaemic and in control patients, this sign is of little value in the diagnosis of pernicious anaemia in the elderly patient.

Fever was not useful in differentiating between the various types of anaemia. Frequently there were obvious reasons for the fever in anaemic patients, a point stressed by Jones and Payne (1960).

Many of the previously reported studies of the clinical manifestations of anaemia were made some decades ago, and represent the classic descriptions of severe and long-standing anaemia of varying aetiology. Our observations on the inci- dence of glossitis and koilonychia in iron-deficiency anaemia differ substantially from these earlier studies. This may reflect a trend towards more prompt diagnosis and more effective treatment of iron-deficiency anaemia at the present time, with a consequent reduction in its chronicity and severity.

We wish to thank Dr. Gillian Fowler for much help and advice in the statistical analysis, and the physicians of Aberdeen General Hospitals for access to patients under their care.

\section{REFERENCES}

Beveridge, B. R., Bannerman, R. M., Evanson, J. M., and Witts, L. J. (1965). Quarterly fournal of Medicine, 34, 145

Britton, C. J. C. (1963). Disorders of the Blood, 9th ed. London, Churchill.

Davidson, L. S. P., and Fullerton, H. W. (1938). Edinburgh Medical fournal, 45, 1 .

Davies, D. T. (1931). Lancet, 2, 385.

Davies, D. T. (1935). Annals of Internal Medicine, 63, 951.

Hall, C. A. (1965). Annals of Internal Medicine, 63, 951.

Jones, E. (1938). American fournal of Medical Sciences, 195, 150.

Jones, R. V., and Payne, R. W. (1960). Practitioner, 184, 618

Kemsley, W. F. F., Billewicz, W. Z., and Thomson, A. M. (1962) British fournal of Preventive and Social Medicine, 16, 189.

Ramsay, W. N. M. (1957a). Clinica Chimica Acta, 2, 214.

Ramsay, W. N. M. (1957b). Clinica Chimica Acta, 2, 221.

Read, A. E. and Asher, R. (1956). Lancet, 1, 882.

Read, A. E., and Asher, R. (1956), Lancet, 1, 882. 1002.

Seaton, D. A., and Goldberg, A. (1960), Lancet,

Spray, G. H. (1955). Clinical Science, 14, 661. 14,335 .

Wintrobe, M. M. (1967). Clinical Haematology, 6th ed. London, Kimpton.

Wintrobe, M. M., and Beebe, R. T. (1933). Medicine, 21, 187.

Witts, L. J. (1930). Guy's Hospital Reports, 10, 253.

Wood, M. M., and Elwood, P. C. (1966). British fournal of Preventive and Social Medicine, 20, 117.

\title{
Immunoglobulins and the X-Chromosome
}

\author{
K. RHODES,* M.D. ; R. L. MARKHAM, $\dagger$ B.SC. ; P. M. MAXWELL $\ddagger ;$ M. E. MONK-JONES,§ M.SC.
}

Summary : Serum levels of immunoglobulins (Ig) G, M, $S$ and $A$ were determined in 28 women with an additional X-chromosome (XXX), and in equal numbers of age-matched normal women and men. Mean IgM levels were found to be highest in the $\mathbf{X X X}$ group, intermediate in normal women, and lowest in men; these differences were statistically significant. Mean IgM values obtained from seven XXY and three XXXY cases were almost identical with those of normal women and XXX women respectively. No such sex linkage was observed for IgA and IgG levels. These results support the suggestion that the serum level of $\operatorname{IgM}$ is related to the number of $\mathrm{X}$ chromosomes present.

\section{Introduction}

In an investigation comparing immunological responses of normal persons with those of patients suffering from rheumatoid arthritis we found that mean serum IgM levels of women were significantly higher than those of men among both patients and healthy persons (Rhodes et al., 1969). Higher female IgM levels compared with male have also been reported by Butter- worth et al. (1967), Rowe et al. (1968), and others, and the occurrence of this phenomenon in diverse populations suggests that it is due to hereditary rather than environmental factors. Evidence for the genetic control of immunoglobulin levels comes from the work of Cohen et al. (1961), who showed that higher rates of synthesis in American Negroes than in Caucasians persisted in different environments. The presence of apparently sex-linked alterations in the level of one immunoglobulin alone has, to our knowledge, not been hitherto reported. The predominant male incidence of congenital agammaglobulinaemia reveals sex linkage, but the antibody deficiency usually relates to low concentrations of IgG and IgA as well as of IgM. Other immunoglobulin-deficiency states such as acquired agammaglobulinaemia and Swiss type agammaglobulinaemia, though genetically determined (Tobler and Cottier, 1958 ; Hitzig and Willi, 1961; Kamin et al., 1968) are generally not thought to be sex-linked.

* Formerly Director of Rheumatology Laboratory.

+ Biochemist.

$¥$ Senior Research Technician.

Department of Physical Medicine and Rheumatology, Royal Free Hospital, London N.W.3.

$\checkmark$ Senior Lecturer, Department of Physics, Royal Free Hospital Medical School, London W.C.1. 